Article

\title{
The Advocacy of Feelings: Emotions in EU-Based Civil Society Organizations' Strategies
}

\author{
Rosa Sanchez Salgado \\ Department of Political Science, University of Amsterdam, 1018 WV Amsterdam, The Netherlands; \\ E-Mail: r.m.sanchez@uva.nl
}

Submitted: 30 March 2018 | Accepted: 23 October 2018 | Published: 28 December 2018

\begin{abstract}
European Union (EU)-based Civil Society Organizations (CSOs) are usually pictured as well-established professionalized actors basing their advocacy strategies on the provision of expertise. Does the focus on expertise imply the removal of emotions and feelings from political communication? Following the emotion turn in social movement and collective action studies, this article investigates how and why EU-based CSOs use emotions in their advocacy strategies. The article shows first how CSOs use rhetorical appeals to emotions and rhetorical appeals to reason in their communication. Secondly, the focus is directed to emotion-inspired advocacy strategies, namely blaming and shaming, fear-mongering and boosting. The choice of rhetorical appeals and strategies is mainly explained by three different inter-related factors: the logics of influence, the logics of membership and media logics. Empirical data is drawn from a content analysis of press releases and policy documents of environmental (climate change) and human rights (refugee crisis) CSOs active at the EU level and from semi-structured interviews with key CSO representatives.
\end{abstract}

\section{Keywords}

civil society organizations; emotions; European Union; feelings; interest groups

Issue

This article is part of the issue "Interdisciplinary Approaches to Studying Emotions within Politics and International Relations", edited by Alex Prior (University of Leeds, UK) and Yuri van Hoef (Utrecht University, The Netherlands).

(C) 2018 by the author; licensee Cogitatio (Lisbon, Portugal). This article is licensed under a Creative Commons Attribution 4.0 International License (CC BY).

\section{Introduction}

Do Civil Society Organizations (CSOs) act from the heart or from the head? After the end of the 1960s, emotions tended to play almost no role in the understanding of social movements and collective action, since rational, structural and organizational models dominated political analysis (Calhoun, 2001; Goodwin, Jasper, \& Poletta, 2001). Since a few years, it may be the turn of social movements and emotions (Collins, 2001). Emotions have indeed attracted increasing scholarly attention in the 2000s, even if they have not deeply transformed the understanding of sociological and political theory (Calhoun, 2001).

Despite this increasing interest, many sub-disciplines within the field of political science, such as European studies or interest groups research, have not dedicated much attention to the role of emotions. Emotions are a key factor to ensure consent and social conformity and as such, they could help to address central questions in interest-group research in the European context, such as the democratic deficit and the legitimacy gap. Regarding the particular topic of CSOs in the European Union (EU), the emphasis has been placed on their expertise, their consensus-seeking strategies and their professionalism, and thus, little attention has been given to the role that emotions might have played in their advocacy strategies. A better understanding of the role of emotions can help explain how CSOs engage in dynamics of justification and persuasion. This article also constitutes an interesting addition to current literature on framing processes. Current research on framing tends to focus on the cognitive and normative aspects and there is considerably less research about the interaction between framing processes 
and emotions (Gross \& D'Ambrosio, 2004; Lecheler, Bos, \& Vliegenthart, 2015).

To contribute to the development of knowledge on the role of emotions in advocacy activities, the present article answers the following research question: how do EU-based CSOs use emotions in their advocacy strategies? This question is further developed in the following sub-questions: To what extent do EU-based CSOs use rhetoric appeals to reason and rhetoric appeals to emotion in their political communication? If CSOs use appeals to emotions, how do they use them and why do they use them within the framework of different strategies?

This article first briefly introduces the study of emotions in social movement research. Secondly, I provide a preliminary analytical framework to study the use of emotions by CSOs and I discuss the methodology and the data collected. The empirical part applies the proposed framework. It shows how and why the analyzed CSOs use appeals to reason and emotions in their political communication and to which extent these CSOs use emotions in advocacy strategies including examples such as blaming and shaming, fear mongering and boosting.

\section{Studying the Role of Emotions in EU-Based CSOs' Advocacy}

This section introduces first the main concepts used in this article, namely CSOs and emotions, and discusses very briefly the study of emotions in social movements and collective action research. I also provide a preliminary analytical framework to study the use of emotions by CSOs in their communication and advocacy strategies.

\subsection{CSOs, Emotions and the Study of Collective Action}

Both the concept of CSOs and emotion are highly contested. Regarding CSOs, I opt for a definition that focuses on their public purpose (Sanchez Salgado, 2014). CSOs stand out for their normative dimension since they support values such as equality, justice and solidarity (Cohen \& Arato, 1992). This definition differs from a broad conception of CSOs including economic and professional organizations and from a strict interpretation of CSOs as exclusively voluntary groups (Jordan, Halpin, \& Maloney, 2004). CSOs analyzed also include organizations funded by public institutions, collective structures or organizations of organizations even when they cannot be considered as traditional voluntary groups.

Regarding emotions, I apply in this article a flexible and inclusive definition. Emotions can originate from cognitive judgments or can be non-conscious responses to bodily states (or a combination of both). The study of emotions differs from the study of the role of values or ideas in the sense that emotions are primed response structures that intervene automatically during the process of adaptation (Popa \& Salanță, 2013).

While studying emotions, disciplines such as political science and sociology tend to emphasize the cognitive di- mension (hypercognitivism). As a complement, my analysis also includes the possibility that emotions may be pre-conscious or even unconscious, since there is sufficient scientific evidence to at least contemplate this possibility (Arias Maldonado, 2016; Damasio, 1999). While the nature of interactions between emotions and cognition (or 'rationality') remains unclear, there seems to be an emerging consensus that the traditional assumption that there is a sharp distinction between emotions and cognition needs to be revisited (as Prior and Van Hoef state in this issue's editorial). It is also agreed that emotions do not have necessarily a negative impact on rational or reasonable decision-making. The way emotions are experienced depends in any case on culture, social class and context.

The study of emotions has increasingly attracted the attention of political scientists (Berezin, 2002; McDermott, 2004; Thompson \& Hoggett, 2012). As may be expected, one of the most prolific subfields is political psychology (Marcus, Mackuen, \& Neuman, 2011; Redlawsk, 2006). Another prolific subfield more directly related to the present study is social movements and collective action (Emirbayer \& Goldberg, 2005; Goodwin et al., 2001; Jasper, 2011). Existing research shows how emotions can help in understanding political behavior in elections and political campaigning, decision-making processes, risk assessment and political involvement.

Existing studies on the role of emotions in collective action and social movements research have been criticized for relying too much on a substantialist conception of emotions, for approaching emotions from a limited number of theoretical perspectives and for assuming the emotional neutrality of established institutions (Emirbayer \& Goldberg, 2005). Most current research indeed conceives emotions as if they were attributes of individuals, at the same level as beliefs, cognitions or interests. Emotional appeals are considered to be very powerful in getting people involved in protest against certain policies or political action against injustices. Emotions are thus usually associated with specific outcomes of collective action. To illustrate with an example, the ability to express anger is considered to be a means to challenge injustices (Jasper, 2011).

Much less has been written about collective emotions (Von Scheve \& Salmela, 2014). Groups can be considered to have emotions when individuals identify with the group (Schmid, 2014) or when there is a joint commitment to the group as a body (Gilbert, 2014). While organizations do not have a body and thus, they do not feel as individuals do, emotions are visible in marketing and internal management strategies (Hochschild, 1983) or more interestingly for this article, in political communication. The institutional role of emotions at the empirical level is also currently underdeveloped in the political field of inquiry. Hochschild's (1983) research showing the significant role of feeling rules in the corporate world continues to be relevant today, but to my knowledge, it has rarely been applied to the study of collective action or politics. 


\subsection{Emotions and EU-Based CSOs Strategies: Analytical Framework}

In this empirical part, I propose first an analytical framework for the descriptive analysis of CSOs' appeals to emotions, and I offer some elements of explanation to help understanding why CSOs may be using such appeals. Second, I establish a link between CSOs' appeals to emotion and their advocacy strategies, illustrating these links with a few examples of emotion-based advocacy strategies.

Rhetorical analysis can help with the operationalization of the study of political communication, making the study of emotions concrete by proposing the study of political arguments as they take place 'in the wild' (Finlayson, 2007, p. 552). Rhetoric is often understood as 'persuasive communications made in contingent and conflictual civic contexts' (Finlayson, 2007, p. 545). Rhetoric is here conceived more broadly, not only as a means of persuasion (merely instrumental), but as fully part of the process of coming to believe something.

Do CSOs use rhetoric appeals to reason or rhetoric appeals to emotion, and if so, why? The distinction between appeals to reason and appeals to emotion differs from the classical distinction between appeals to logos, pathos and ethos. Appeals based on logical justification (logos) often (if not always) include emotional or affective elements. Appeals to ethos (character of speaker) can be both related to reason (when they invoke expertise, formal qualifications or experience) and to emotions, when they involve charisma or affect for a leader. In mainstream research on collective action, the duality between emotion and reason has persisted in more or less subtle ways. Just to give an example, while analyzing CSOs strategies, it is commonly considered that professionalized CSOs focus on expertise provision and social movements and grassroots groups on contentious action. This could be interpreted as a distinction between a few professionalized CSOs basing their arguments on reason and a group of contentious social movements basing their action on emotions.

In the absence of emotions, CSOs would only publish formal and unemotional documents characterized by lack of style, literary tropes or word play with the aim to confer to these publications clarity and a certain gravitas (Finlayson, 2007). This style is usually employed by government and civil servants to confer certain objectivity to their work. In these cases, normative and affective elements may remain, but in a blurred and implicit way. The idea of objectivity and commitment to the better argument has been criticized for ignoring the reality of political communication in the current conflictual, powerladen and inegalitarian context (Bickford, 2011).

Using emotions in political communication can also be considered as part of policy framing, which can be seen as a strategic choice or/and as a result of constraints derived from group characteristics or contextual characteristics (Klüver, Mahoney, \& Opper, 2015). The present article will help to understand the pressures CSOs face while selecting specific frames. This is an interesting contribution to existing research in political communication that places the emphasis on how framing affects individuals. While it has been shown that framing has important effects on emotions and that emotions play an important mediating role (Lecheler et al., 2015), not much is known about the constitutive role that emotions may play in framing dynamics.

Political actors such as CSOs indeed enter into a specific structure of communication that must satisfy certain conventions and institutional codes (Finlayson, 2007). Regarding CSOs, these conventions and institutional codes may come from political institutions, namely government (logic of influence), their members (logic of membership) or from the news media (media logic). The logic of influence requires that interest groups choose frames that allow them to have influence on decision makers (Schmitter \& Streeck, 1981). It implies that interest groups adapt their communication strategies to the particular preferences and beliefs of policy makers. Previous research has shown that EU-based interest groups tend to focus on expertise provision and consensusbuilding strategies (Sanchez Salgado, 2014). Previous research has also shown that public frames are more used when addressing EU departments that deal with public goods giving some credit to the logic of influence (Klüver et al., 2015).

The logic of membership demands from interest groups that they behave in accordance with their constituency (Schmitter \& Streeck, 1981). Public interest groups such as CSOs are more pressured to become known by the public in order to obtain resources from members and supporters. Previous research has confirmed that CSOs tend to stick to public frames following the logic of membership (Klüver et al., 2015).

The media logic (Altheide \& Snow, 1979) leads to a process of mediatization introducing changes in the criteria and rationalities following which interest groups decide upon and act (Brändli, Donges, \& Jentges, 2011). Previous research has shown that interest groups respond and adapt to the media logics with structural changes, but not to the expected extent since the abovementioned logics (membership and influence) also play a relevant role.

Regarding the logic of influence, one would expect that professionalized EU-based CSOs use few appeals to emotion. The European Commission promotes a type of lobbying that is based on information and expertise provision where there seems to be little space for emotional displays. However, following the logic of membership, CSOs may appeal to emotions to promote engagement or mobilization of their members. Radical and contentious repertoires of action (often based on symbols and emotions) are frequently used to strengthen motivations among protestors and to develop feelings of solidarity and belonging (Della Porta \& Caiani, 2009). There are also several reasons why one should expect that media logic promotes rhetorical appeals to emotions in 
advocacy strategies. News reporting is often related to a few bias including personalization and dramatization (Bennett, 2016). Personalization refers to the framing of stories in terms of human interests, which usually includes an emotional angle. Dramatization includes the focus on conflict and negative emotions. Providing drama is usually considered by interest groups as a way to get access to the media and for CSOs this often consists of organizing pseudo-events to provide dramatic visuals and symbolism (Thrall, 2006).

If CSOs use appeals to emotions, how and why do they use them within the framework of different advocacy strategies? Existing studies on lobbying and advocacy strategies have so far proposed several classifications such as the inside/outside strategies model where the role of emotions remains implicit or absent. They rarely focus on emotions with the remarkable exception of blaming and shaming (Kapyla \& Kennedy, 2014). In the following section, I show that appeals to emotions can be directly related to advocacy strategies. On the basis of the empirical material collected for this research, the appeals that seemed to be the most relevant for CSOs advocacy strategies were appeals to shame, appeals to fear and appeals to hope and pride. The emotionbased strategies analyzed in this article are not exhaustive but they provide a first overview of how appeals to emotions can be used within the framework of advocacy strategies.

Compassion filtered through anger is likely to take the form of blaming and shaming or of a public accusation (Kapyla \& Kennedy, 2014). Blaming and shaming consists of appealing to guilt or shame to generate a desired action. While blaming and shaming has often contributed to short-term victories for CSOs (Franklin, 2008), it is also considered that they can hold back CSOs by alienating them from potential allies or be used strategically by policy makers (Van Erp, 2008). There is not much research about how CSOs use fear in their advocacy strategies. The so-called fear-mongering strategy is mostly attributed to journalists and politicians. Fear mongers deploy fear through narrative techniques to normalize errors in reasoning, for example through repetition, through the presentation of isolated occurrences as trends and through misdirection (Glassner, 2004). Last but not least, appeals to hope and pride can be related to boosting. Boosting is an advocacy or lobbying strategy consisting of using media work to enhance the general public's impression of particular policy makers with the purpose of maintaining good relationships with the latter (Trapp \& Laursen, 2017). Within this strategy, CSOs would produce positive content regarding politicians' public image.

\subsection{Methodology and Data Collection and Analysis}

The present article focuses on EU-based CSOs activities in two domains: migration policy (issue of refugee crisis) and environmental policy (issue of climate change). The inclusion of two different policy areas permits to show if there is variation across issues. These policy areas and issues were selected because CSOs have well-established advocacy strategies. Emotions tend to be prominent in both policy areas at the European level, but the presence of emotions in both fields tends to be average, and thus, they can be studied as typical cases. The next sections provide specific information about the corpus of arguments that are going to be analyzed and the context of relations in which they take place.

Regarding the corpus, this analysis covers a total of 267 press releases and short policy documents published online by six well-established EU-based CSOs working on the two topics under analysis (climate change and refugee crisis) ${ }^{1}$ from 2014 to 2017 (see Table 1). The number of documents and timing varies depending on the data availability on each of the websites. The content analysis also covers the last 50 Facebook statuses from every CSO under analysis (year 2017). The Facebook statuses covered all types of issues and not only the ones mentioned above. All data were published in English and analyzed with the qualitative data analysis software Atlas.ti. For the Atlas.ti content analysis I used descriptive markers and automatic coding. First, I read all the documents to identify empirically what could be seen as cognition markers, including words such as statistics, survey, reason or research. Emotion markers included only words referring directly to basic emotions such as fear, compassion and shame. I did not use emotion markers that referred to emotions implicitly or indirectly.

Regarding the context, most policy documents analyzed were addressed to the press or directly to policy makers with the aim to (directly or indirectly through media pressure) persuade policy makers to change their

Table 1. Documents of CSOs analyzed.

\begin{tabular}{lrrrrrrrr}
\hline & \multicolumn{1}{l}{ Al } & \multicolumn{2}{l}{ HRW } & IRC & Greenpeace & FoE & EEB & Total \\
\hline Amount & 86 & 46 & 30 & 50 & 50 & 5 & $\mathbf{2 6 7}$ \\
\hline Years & $2015-16$ & $2015-16$ & $2015-17$ & $2014-17$ & $2014-17$ & $2014-16$ & $2012-17$ \\
\hline
\end{tabular}

Source: elaborated by the author.

\footnotetext{
${ }^{1}$ The press releases and policy documents selected were the ones that CSOs themselves considered to fall within these themes (I used the search function and limited the search to these themes). Regarding the Facebook statuses, it was difficult to order them by topic since Facebook does not have a search function.
} 
course of action in the sense of the goals of the CSOs under analysis. Facebook statuses have a much broader audience, including CSO members and followers. This data was triangulated with five semi-structured interviews with key players working for the direction or communication department of the CSOs analyzed. In contrast to surveys, semi-structured in-depth interviews are flexible. The emphasis is placed on how the interviewee frames and understands issues and events. Since interviewees are left to raise issues and frame them in their own way, there is less risk of bias such as social desirability bias. For example, instead of asking directly if CSOs were employing a fear mongering or boosting strategy, I engaged in a general discussion about the place of fear in CSOs' political communication.

The six environmental and human rights CSOs selected are to be counted among the most well-known EU-based CSOs. They are not only prominent members of the EU umbrellas on their respective topics, such as the Green 10 (environment) or the Human Rights and Democracy Network (HRDN); they also interact frequently with European policy makers. These CSOs are quite similar to other well-established professionalized EU-based CSOs. The selected CSOs differ in their relationships with their membership and in their relationships with public authorities. While all CSOs under analysis have sufficient resources to make noise and make news (Thrall, 2006), they are well-known for approaching the media in rather different ways. This variation will help understanding better the different effects of the logics of influence, membership and media under analysis.

Amnesty International (AI), Human Rights Watch (HRW) and Greenpeace EU office are well-established popular organizations getting most of their support from their large number of donors and supporters. Organizations like $\mathrm{Al}$ and Greenpeace claim to reach a large number of members and supporters ( 7 million and 3 million people respectively). With only 1,000 volunteers and ambassadors, the logic of membership is expected to play a lesser role for HRW. HRW is however known to be an organization focused on getting media attention, and for this reason, the media logic may play a relevant role. Organizations such as Friends of the Earth (FoE), International Rescue Committee (IRC) and European Environmental Bureau (EEB) are funded by public bodies, namely European institutions. For this reason, the logic of influence may unfold differently for these organizations. They are expected to be less dependent on the logic of membership since their constituencies do not provide them with the resources they need to operate. However, FoE is known for its connections with social movements, and in this sense, the logic of membership may play a relevant role. Most CSOs have are very active on the topics under analysis. Only EEB, well known for its work on topics such as circular economy, had so far little opportunity to focus on Climate change, which explains the reduced number of press releases published on this topic. While also a member of the HRDN, IRC can also be considered as a humanitarian CSOs more focused on service delivery than on the publication of documents.

\section{Rhetorical Appeals by EU-Based CSOs}

In this empirical section I discuss the presence of appeals to reason and appeals to emotion in the document analysis. I first present the results of the descriptive content analysis showing the frequencies of the presence of emotions in the different documents. Secondly the attention is turned to the explanations provided in the analytical framework: logic of influence, membership and media logic. For a better understanding of the dynamics at work, and in-depth content analysis has been triangulated with in-depth interviews and placed in context.

\subsection{Complementarity between Rhetorical Appeals to Emotions and Rhetorical Appeals to Reason}

Data collected suggest that EU-based CSOs use both rhetorical appeals to reason and emotion. Tables 2 and 3-displayed here for descriptive purposes-show how frequently emotion and cognitive markers (as initial indicators of appeals to reason and emotion) appeared in the documents analyzed. These tables showing emotion and cognitive markers should be understood as the tip of the iceberg. CSOs analyzed also used other methods to display emotions in their documents such as figures of speech or expressive speech acts, including metaphors and nomination strategies. While referring to emotional content during the interviews, $\mathrm{CSO}$ staff also mentioned storytelling, pictures, videos and examples.

Regarding cognitive markers, $\mathrm{CSO}$ s used logical argumentation and reasoning which is not clearly reflected in the Atlas.ti analysis. CSOs also back up their assertions and statements with citations to authority, including mainly international organizations, public authorities and the press. CSOs have also commissioned surveys by leading research companies or consultancies (Ipsos Mori or Globe Scan) to support their points. More interestingly, when the documentation is analyzed carefully, the distinction between emotions and facts is problematic. Indeed, most CSOs' scientific reports and documents do not only report facts but they also report the-often emotionally - charged testimonies of victims and survivors.

Data show that the choice for expertise does not necessarily imply the exclusion of emotions and feelings. Preliminary research also shows that this finding can be replicated among national and local CSOs such as Secours Catholique and Cimade in France (Sanchez Salgado, 2017). While these analysis show that emotions and cognitive markers coexist, further research could focus on collecting additional quantitative data to establish to which extent these two types of appeals are correlated.

Human Rights CSOs working on migrants used emotion markers frequently (see Table 2). Another interest- 
Table 2. Human rights and humanitarian CSOs (refugee crisis).

\begin{tabular}{lllll}
\hline Markers & Al & HRW & Rescue & Total \\
\hline Emotion markers & $83(0.96)^{2}$ & $48(1,04)$ & $32(1,06)$ & 163 \\
Compassion & $6(7,22 \%)$ & $7(14,58 \%)$ & $4(12,5 \%)$ & $17(10,42 \%)$ \\
Fear & $22(26,50 \%)$ & $14(29,17 \%)$ & $4(12,5 \%)$ & $40(24,54 \%)$ \\
Hate & $7(8,43 \%)$ & $6(12,5 \%)$ & $0(0 \%)$ & $13(7,97 \%)$ \\
Hope & $12(14,46 \%)$ & $9(18,75 \%)$ & $9(28,12 \%)$ & $30(18,40 \%)$ \\
Shame & $16(19,28 \%)$ & $3(6,25 \%)$ & $2(6,25 \%)$ & $21(12,88 \%)$ \\
Suffering & $15(18,07 \%)$ & $5(10,42 \%)$ & $2(6,25 \%)$ & $22(13,50 \%)$ \\
Others & $5(6,02 \%)$ & $4(8,33 \%)$ & $11(34,37 \%)$ & $20(12,27 \%)$ \\
\hline Cognitive markers & $78(0,9)$ & $34(0,74)$ & $20(0,66)$ & 132 \\
Reason & $6(7,69 \%)$ & $11(32,35 \%)$ & $3(15 \%)$ & $20(15,15 \%)$ \\
Research & $48(61,54 \%)$ & $19(55,88 \%)$ & $3(15 \%)$ & $70(53,03 \%)$ \\
Statistics & $11(14,10 \%)$ & $1(2,94 \%)$ & $5(25 \%)$ & $17(12,88 \%)$ \\
Survey & $7(8,97 \%)$ & $0(0 \%)$ & $5(25 \%)$ & $12(9,09 \%)$ \\
Others & $6(7,69 \%)$ & $3(8,82 \%)$ & $4(20 \%)$ & $13(9,85 \%)$ \\
\hline
\end{tabular}

Source: elaborated by the author ${ }^{3}$.

Table 3. Environmental CSOs (climate change).

\begin{tabular}{lllll}
\hline & Greenpeace & FoE EU & EEB & ALL \\
\hline Emotions & $16(0,32)$ & $59(1,18)$ & $2(0,4)$ & 77 \\
Fear & $2(12,5 \%)$ & $10(16,9 \%)$ & $0(0 \%)$ & $12(15,58 \%)$ \\
Hope & $0(0 \%)$ & $12(20,33 \%)$ & $0(0 \%)$ & $12(15,58 \%)$ \\
Others & $14(87,5 \%)$ & $37(62,7 \%)$ & $2(100 \%)$ & $53(68,83 \%)$ \\
\hline Reason & $20(0,4)$ & $30(0,6)$ & $3(0,6)$ & 50 \\
Reason & $2(10 \%)$ & $9(30 \%)$ & $1(33,34 \%)$ & $11(22 \%)$ \\
Research & $8(40 \%)$ & $11(36,66 \%)$ & $2(66,67 \%)$ & $19(38 \%)$ \\
Expert & $8(40 \%)$ & $2(6,67 \%)$ & $0(0 \%)$ & $10(20 \%)$ \\
Others & $2(10 \%)$ & $8(26,67 \%)$ & $0(0 \%)$ & $10(20 \%)$ \\
\hline
\end{tabular}

Source: elaborated by the author.

ing finding is that rhetorical appeals varied per policy area since CSOs use different types of emotional and cognitive markers. Compassion and shame were frequently used by human rights CSOs, while they were almost absent in the documents published by environmental CSOs. Data also showed that there are differences among CSOs, which is particularly evident in the environmental policy field. FoE used significantly more appeals to emotions in the press releases than Greenpeace and EBB. The press releases of these two last organizations are, as general rule, much more technical. Having said this, emotional or catchy expressions and metaphors were still used in the titles, quotes of staff or campaigners.

Table 4 confirms two main expectations: that there are differences depending on the communication channel (and the audience targeted) and that there are differences depending on the type of $\mathrm{CSO}^{4}$. Since the nature of press releases and of Facebook statuses is very different (press releases contain more words), it is difficult to say in which channel emotions are the most present. However, some CSOs, such as IRC used more emotions on Facebook than on press releases (at least in comparison with other CSOs). The main finding is that environmental CSOs displayed rather positive emotional messages on Facebook and used regularly emojis. While hope and positive emotions are not absent, Human Rights NGOs also used Facebook statuses to appeal to what are usually considered as negative emotions. This is in line with their strategy of requesting urgent action from their members to place pressure on authorities responsible for human rights violations.

\subsection{Explaining the Use of Appeals to Emotions}

All the factors mentioned highlighted by previous literature (logic of influence, logic of membership and media logic) played a relevant role as expected. These factors were combined in different ways and thus, CSOs were un-

\footnotetext{
${ }^{2}$ To give an idea of the relative important of emotions I added the average number of markers per press release.

${ }^{3}$ To avoid an excessively long table, only the emotion and cognitive markers that appeared more than 10 times have been included and the rest have been placed in the others category.

${ }^{4}$ Again, while interpreting the results of Table 4, it is important to keep in mind that emotional markers are just the tip of the iceberg when it refers to the emotional content of Facebook statuses, since they often include pictures and videos.
} 
Table 4. Emotion markers in 50 last Facebook statuses 2017 (all topics included).

\begin{tabular}{|c|c|c|c|c|c|c|c|}
\hline & EEB & FoE & $\begin{array}{l}\text { Greenpeace } \\
\text { International }\end{array}$ & IRC & Al & HRW & CSOs \\
\hline Sad & 0 & 0 & 0 & 0 & 0 & 0 & 0 \\
\hline Shame & 0 & 0 & 0 & 0 & 2 & 0 & 2 \\
\hline Disturbing & 0 & 0 & 0 & 0 & 0 & 2 & 2 \\
\hline Fear & 0 & 0 & 0 & 0 & 1 & 0 & 1 \\
\hline Happy & 3 & 2 & 1 & 3 & 1 & 0 & 10 \\
\hline Hope & 2 & 1 & 1 & 4 & 2 & 1 & 11 \\
\hline Love & 0 & 1 & 1 & 1 & 1 & 0 & 4 \\
\hline Passion & 0 & 0 & 0 & 1 & 2 & 0 & 3 \\
\hline Sad & 0 & 0 & 0 & 0 & 0 & 0 & 0 \\
\hline Shame & 0 & 0 & 0 & 0 & 2 & 0 & 2 \\
\hline EMO & 5 & 4 & 3 & 14 & 9 & 3 & 38 \\
\hline Emoji & 4 & 7 & 5 & 1 & 0 & 0 & 17 \\
\hline
\end{tabular}

Source: elaborated by the author.

der contradictory pressures. On the one hand, policy officials (logic of influence) often imposed a discursive style in which emotions had no place. On the other hand, CSOs also believed that strong emotions were needed to show that there was an urgent problem that required the attention of their members and of the news (logic of membership and media logic).

As expected, the logic of influence led to more technical and formal documents based on facts. The logics of influence was particularly visible in the case of Greenpeace EU office, because-contrary to the other organizations analyzed-this Greenpeace office only addressed policy makers. While communicating with the EU, especially the Commission, Greenpeace did not put emotions in the forefront. According to the Greenpeace representative:

In the European Commission is evident in the discourse: they use the word emotion to disqualify an opponent, so if you say something they will say let's not get emotional or we are not dealing here with emotions, we are dealing with facts...the attempt is to say that what you say does not matter because that's not factual. That's their approach, they have a very theoretical and analytical approach. (Interview 3)

While it may be less evident (since combined with other logics), the logic of influence was also relevant for the other CSOs. FoE, for example, considered that emotions do not work when trying to influence policy makers like the Commission but that they work when you try to shape the public debate (Interview 1).

As expected, the logic of membership led to the presence of emotional content. FoE's strong links with social movements seem to have contributed to the presence of emotional content in their political communication. The FoE representatives explained that their role was to take grass-roots discussions to decision makers, reach the public and inform the democratic debate (Interview 1). EBB representatives also mentioned frequently their democratic base, but due to their members' lack of resources, the logic of membership seemed less relevant in the shaping of their communication strategy (Interview 4). However, an increasing interest in addressing directly the public led the EBB to elaborate a new communication strategy with more space for emotional content.

All those interviewed, especially those working in communication departments with a journalistic background, were well aware of the media logic. The emphasis was often placed on dynamics of personalization with an emotional content. For example, on the topic of the refugee crisis, Al would focus on families, since all of us have families and this was expected to make people feel empathy for refugees. Personalization and the use emotions was also considered to be important to appeal to a sense of humanity and compassion, as well as to raise sympathy (Interviews 2 and 5). Adaptation in terms of the dramatization bias was less clear. Some CSOs representatives expressed reluctance to focus on dramatic negative stories, while others considered that you can create a drama effect without necessarily focusing on the negative aspects of a situation. All interviewees explained that their organizations increasingly included in their communication strategies elements that contribute to dramatization (Bennett, 2016) such as videos, graphics, drawings and multimedia, etc. Following this new way of presenting information, a CSO representative even affirmed that they had been transformed into a 'journalistic organization' (Interview 5). Interviewees also adapted to the media logic in more organizational (and not only content related ways). For example, they emphasized the need to react quickly and to write press releases in a way that would be the most useful for journalists. At Al, to keep the media pace, press releases were even written before events took place with several scenarios in mind (Interview 2).

The different logics (membership, media and influence) also depended on the issue at hand. Human Rights CSOs working on refugees were more prone to use ap- 
peals to emotions in their communication strategies. In the interviews, Human Rights CSOs affirmed than using strong emotions was a way to humanize the issues so the broader public and policy-makers could understand that there is really an urgent problem that needs to be addressed (Interviews 2 and 5). The FoE representative interviewed thought that their focus on a justice and human rights perspective may explain why they used more emotional content in their communication (Interview 1). On top of this, the use of emotions in political communication may be more problematic for environmental CSOs. In any case, environmental CSO representatives generally placed more emphasis on negative reactions from policy-makers.

\section{Emotional Appeals in CSOs' Advocacy Strategies}

Without being exhaustive, the next section shows how appeals to emotions are used in CSOs' advocacy strategies. Based on the empirical material, the emotional appeals that seemed to be the most frequent or relevant for advocacy strategies were appeals to shame (blaming and shaming strategy), appeals to fear (fear mongering strategy) and appeals to hope and pride (boosting strategy).

\subsection{The Complexity of Blaming and Shaming}

The blaming and shaming strategy is clearly visible in the case of the refugee crisis (Box 1). The explicit emotional marker 'shame' appears 21 times in this issue, which is much more than the average emotional and cognitive marker (see Table 2). The word shame is mostly used to refer to Europe or to the EU and its member states (17 times out of 21).

When asked if they used a blaming or shaming strategy, the representative of Al responded 'of course we use blaming and shaming, that's our battle' (Interview 2).
The HRW representative also confirmed that blaming and shaming is just 'what we do' (Interview 5). Blaming and shaming is thus a conscious strategy used systematically by the human rights CSOs analyzed. However, CSOs representatives expressed some doubts about the usefulness of blaming and shaming in the new political context since a new generation of populist politicians tended to feel proud about facts that in other times would have been perceived as shameful (Interview 2 and 5). Despite these doubts, blaming and shaming continued to be considered one of the main strategies with overall positive results when you looked at the broader picture.

In the environmental policy field the use of blaming and shaming is not so evident while looking at emotion markers alone. FoE is the only CSO that seems to visibly engage in the blaming of policy makers through different forms, including wordsplay and metaphors. Public authorities are pictured as hypocrites (5 occurrences), dirty (30 occurrences) 5 and employing 'shallow speeches' or referring to the 'blatant emptiness of speeches'. Governments are also blamed using metaphors such as their 'infatuation with gas' and 'plastic obsession'. FoE's representatives confirmed that they indeed used a blaming and shaming strategy in a few occasions but that they were very careful to place the blame accurately (e.g., on a particular faction of the Parliament) to avoid feeding discourses of the type all is the EU's fault (Interview 1).

Greenpeace and EBB used blaming and shaming only in specific cases, which can explain why this was not so visible in their documents. The EBB representative affirmed that they used blaming and shaming sometimes, but that they would think hard before because they did not want to undermine their relationships with policymakers and business (Interview 4). Greenpeace EU office representative explained that they used blaming and shaming, but only in very specific occasions and with a very specific target and objective in mind (In-

Box 1. Examples of the use of emotion marker 'shame'.

Before it was demolished at the end of October, the sprawling migrant camp in Calais had become a symbol of Europe's shame. (HRW, November 22, 2016)

European Union (EU) governments should hang their heads in shame at the ongoing reluctance of many to ensure a collective and concerted search and rescue operation in the Mediterranean, said Amnesty International. (Al, 12 March 2015)

Europe's response to the refugee crisis within its borders is shamefully inadequate. (IRC, November 4, 2015)

Box 2. Examples of blaming by environmental CSOs.

As the dirtiest kid in the European Union class, the Netherlands has also been neglecting its duty to combat climate change for a long time. (FoE)

Greenpeace EU legal adviser Andrea Carta said: “The Commission is being spectacularly irresponsible: it's allowing massive subsidies for a project backed by a government that openly challenges the importance of independent oversight for nuclear safety".

\footnotetext{
${ }^{5}$ Most of the time dirty is used to refer to dirty energies such as coal, etc. However, FoE also uses the term dirty to refer to public authorities and corporations.
} 
terview 3). For example, during the process of adoption of the REACH directive, Greenpeace EU office published a rather shocking picture where Commissioner Gunter Verheugen could be seen feeding chemical products to a baby, while President Barroso looked passively. This picture had a very specific purpose: to make other Commission and EU officials feel ashamed about the stand of Verheugen regarding this issue, including his links with German industry. The caution of these two organizations in using blaming and shaming seemed welljustified since they affirmed that when they used blaming and shaming they usually got strong (even personal) reactions from their targets.

\subsection{Avoiding Fear Mongering? A Complex Balance between Fear and Hope}

While the emotion marker fear appeared quite frequently in the documents of some CSOs under analysis, this does not seem to be part of a strategy of fear mongering (as previously defined). CSOs representatives interviewed were conscious that fear was present in their work, but they affirmed that they were not consciously trying to spread fear. They insisted that what they were saying was faithful to the truth and supported by facts. In addition to this, the interviewed affirmed that they usually tried to downplay fear by focusing on more positive and hopeful facts. This seems to be confirmed by the content analysis that shows-especially for environmental CSOs - that the word marker hope is used as frequently as the word marker fear.

CSOs working on the refugee crisis used the word fear more frequently than environmental CSOs. When using the word fear, human rights CSOs aimed at combating the fear mongering strategy used by politicians, rather than the contrary. The emotion 'fear' was indeed frequently used to refer to public authorities (15 times). CSOs would argue that current public policy towards migrants is based on fear. The majority of references to fear referred however to the fear of refugees and migrants and seemed to be directed to move readers and policy makers to compassion rather than to spread fear itself.

While the use of the word marker fear by FoE does not seem relevant ${ }^{6}$, when reading in-depth FoE's press releases, it could be eventually interpreted that they engage occasionally in fear mongering using words such as horrendous and devastating or metaphors such as 'the world is still on a collision course with climate change'. Rather than fear mongering, this could also be interpreted as a faithful description of reality based on current scientific evidence. FoE representatives considered they were unfairly accused of fear mongering and because of this, they took special care of supporting their arguments with data and facts. It could also be argued that environmental organizations are actually refraining themselves from spreading fear. Environmental CSOs claimed that they did not share all the information they had about the current situation regarding climate change because this would give such a fearful picture that people and policy-makers would fall in despair. Finding the right balance between fear and hope seemed to be a concern for CSOs representatives interviewed, but not always one easy to solve:

I think we are also kind of aware that by raising fear without giving directions to what the solution really is can lead to all sorts of false solutions. You know, putting blame in the wrong place and I am thinking about some of the riots of the far right-wing populism which is all about fear mongering but without telling the genuine solution at all. (Interview 1)

\subsection{Boosting: Encouraging Members to Promote Change}

In the documents analyzed, Greenpeace EU office praises institutions or policy makers more frequently than the rest of CSOs. Greenpeace representative affirmed that praising policy makers was done to be fair (giving praise when it was deserved) rather than within the context of a boosting strategy (Interview 3). This fair play could also help Greenpeace to be heard when they were more critical. Praising the EU was also related to Greenpeace's global assessment according to which the EU, while having major problems, had very developed environmental legislation compared to other countries. Within this context, Greenpeace wanted to highlight the positive role of the EU.

Box 3. Examples of use of emotion marker fear by CSOs.

Leaders need to be serious about identifying and removing people who pose a threat or who don't need protection, but they should not foment fears and prejudice that play into the hands of extremists and risk blinding host communities to their common humanity. (HRW, March 4, 2016)

The EU needs to be responding not with fear and fences, but in the best tradition of the values it purports to hold dear. (Al, November, 2015)

This is relevant in countries like Greece, where the fear is that refugees bring economic burden, but the reality could be of benefit. (IRC, September, 2016)

\footnotetext{
${ }^{6}$ Most occurrences were placed in a poem (7 occurrences) where the author was claiming not to be afraid.
} 
Box 4. Examples of boosting.

Li Shuo, climate policy advisor at Greenpeace East Asia, said: "We are seeing much needed leadership emerge from the EU and China today". (Greenpeace, June, 2017)

A new plan by key members of the European Parliament would help the EU retake global leadership on climate change, just as the US dithers on its commitments under the Paris climate agreement, said Greenpeace.

Sebastien Risso, Greenpeace EU forest policy director, said: "The Parliament is right to recognise the huge responsibility that the EU has to stop deforestation, and how important this is for climate action and sustainable development. (Greenpeace, April, 2017)

Box 5. Examples of boosting directed to members (from Facebook).

Over the next year, you have the opportunity to make history. You're going to help create the largest protected area on Earth. (Greenpeace, Facebook post, December 29, 2017)

There's an emerging, strong, diverse, inspiring movement coming together to demand that the transition from an extractive economy to a regenerative one is fair and fast. (FoE, November 29, 2017)

Your words have real power-the power to comfort, heal and even set people free. (AI, November 27, 2017)

While this did not appear very frequently in the documents analyzed, other CSO representatives also affirmed that they praise the positive steps by public authorities when they act as required. One might argue that organizations such as Al and HRW might-all in all-praise policy makers as much as Greenpeace, but that in this specific issue (refugee crisis) there were fewer occasions to praise policy makers. According to a CSO representative (Interview 4) the European level did not seem the most adapted for the application of a boosting strategy because elections are not as relevant as at the national level and because there were less opportunities to make policy makers believe they would be remembered for their legacy.

However, boosting members and the public in general is part of the strategy of the CSOs analyzed and this is mainly done through non-traditional channels of communication such as Facebook. In their communication, CSOs are actively trying to empower citizens and to make them feel proud of doing something good for human rights or the environment. CSOs also consciously celebrated their victories and displayed the power of their network and their movement.

\section{Conclusion: Breaking Down the Emotional Paradox}

This article has shown the important and ambiguous role that emotions play in CSOs' advocacy strategies. The descriptive content analysis showed that CSOs tend to combine the use of appeals to emotions with appeals to cognition in their communication. The emphasis on emotions depended on different factors such as the logics of influence, the logics of membership and the media logic. While the logics of influence led to less emotional content, the logic of membership and the media logic seemed to increase the emotional content in CSOs political communication.

CSOs are thus confronted to contradictory pressures. On the one hand, activists know that politics is about emotions and that they need strong emotional appeals to make problems really matter. This translates in the use of emotions in their communication and the use of emotion-inspired advocacy strategies, such as blaming and shaming. On the other hand, the perception that emotional expression can be detrimental for rational and objective decision-making is also prevalent among activists. For this reason, activists tend to downplay certain emotions. This apparent paradox is supported by the prejudice according to which emotions interfere with the proper functioning of rationality. If emotions were recognized as an effective way to reach a rational view, these two logics would be more consciously (and possibly effectively) combined. The recognition of emotions as a way to reach a rational view would also led to question the current position of public authorities that rely exclusively on cognition. It could also help promoting the further exploration of the nuances of emotions in advocacy strategies.

This research has also shown the relevance of emotions in advocacy strategies. Blaming and shaming seems to be a very relevant strategy for CSOs with many variants. Does blaming and shaming really intend to shame policy makers (as suggested by the definition of this concept) or does it rather intend to make them feel afraid for their reputation? Do different types of blaming and shaming have different effects? This article also showed that CSOs do not seem to be aiming at spreading fear within a framework of a fear-mongering strategy. It also showed that managing fear in CSOs' advocacy strategies raises complex issues. Should CSOs share all the information they have regarding the climate situation and human rights violations, even if this information may lead to discouragement and despair?

Last but not least, this article also showed that a clear boosting strategy does not seem to be systematically applied with policy makers. CSOs affirm they just praise them occasionally to be fair and to increase their credibility. CSOs are however greatly involved in promot- 
ing good feelings among their members and supporters. Further research could analyze how effective boosting is to get people more involved in the causes that CSOs are defending.

These conclusions also raise important normative questions. Is it acceptable to use blame or fear to induce a change of behavior? While triggering fear to manipulate behaviour is generally-and probably rightlyperceived as wrong, it seems reasonable-and probably right-to inform policy makers of the consequences of their actions. If these consequences are negative or dangerous, fear may be needed to adopt the most adequate policy solutions. Thus, while fear can certainly disrupt politics and decision-making, it may also be a form of wisdom in the face of real danger.

\section{Acknowledgments}

My special thanks to the CSO representatives that granted me an interview despite their busy schedules. All my thanks to Anna Ritter for her help with the data collection and to Jonathan Zeitlin for the revision of early drafts. An earlier version of this article was presented in the Low Countries seminar organized in Amsterdam in February 2018. I am grateful to the participants to this seminar and to the Politics and Governance's anonymous reviewers for the careful reading of this article and for the constructive suggestions and remarks that considerably contributed to its improvement.

\section{Conflict of Interests}

The author declares no conflict of interests.

\section{References}

Altheide, D. L., \& Snow, R. P. (1979). Media logic. London: Sage.

Arias Maldonado, M. (2016). La democracia sentimental [Sentimental Democracy]. Barcelona: Pagina indomita.

Bennett, L. W. (2016). News. The politics of illusion. Chicago, IL: CUP.

Berezin, M. (2002). Secure states: Toward a political sociology of emotion. In J. Barbalet (Ed.), Emotions and sociology (pp. 32-52). Oxford: Blackwell.

Bickford, S. (2011). Emotion talk and political judgment. The Journal of Politics, 73(4),1025-1037.

Brändli, M., Donges, P., \& Jentges, E. (2011). Mediainduced change in political organizations? Interest groups and their reaction to the media. Paper presented at 6th ECPR general conference, Reykjavik.

Calhoun, C. (2001). Putting emotions in their place. In J. Goodwin, J. Jasper, \& F. Poletta (Eds.), Passionate politics (pp. 45-57). Chicago, IL: Chicago University Press.

Cohen, J. L., \& Arato, A. (1992). Civil society and political theory. Massachusetts, MA: MIT Press.
Collins, R. (2001). Social movements and the focus of emotional attention. In J. Goodwin, J. M. Jasper, \& F. Polleta (Eds.), Passionate politics, emotions and social movements (pp. 27-44). London: University of Chicago Press.

Damasio, A. (1999). The feeling of what happens. Orlando, FL: Houghtton Mifflin.

Della Porta, D., \& Caiani, M. (2009). Social movements and Europeanization. Oxford: Oxford University Press.

Emirbayer, M., \& Goldberg, C. A. (2005). Pragmatism, Bourdieu, and collective emotions in contentious politics. Theory and Society, 34, 469-518.

Finlayson, A. (2007). From beliefs to arguments: Interpretive methodology and rhetorical political analysis. BJPIR, 9, 545-563.

Franklin, J. (2008). Shame on you: The impact of human rights criticism on political repression in Latin America. International Studies Quarterly, 52(1), 187-211.

Gilbert, M. (2014). How we feel: Understanding everyday collective emotion ascription. In C. Von Scheve, M. \& Salmela (Eds.), Collective emotions (pp. 17-31). Oxford: Oxford University Press.

Glassner, B. (2004). Narrative techniques of fear mongering. Social Research, 71(4), 819-826.

Goodwin, J., Jasper, J., \& Poletta., F. (2001). Passionate politics, emotions and social movements. Chicago, IL: Chicago University Press.

Gross, K., \& D’Ambrosio, L. (2004). Framing emotional response. Political Psychology, 25(1), 1-29.

Hochschild, A. R. (1983). The managed heart. London: University of California Press.

Jasper, J. M. (2011). Emotions and social movements: Twenty years of theory and research. Annual Review of Sociology, 37(1), 285-303.

Jordan, G., Halpin, D., \& Maloney, W. (2004). Defining interests: Disambiguation and the need for new distinctions. BJPIR, 6, 195-212.

Kapyla, J., \& Kennedy, D. (2014). Cruel to care? Investigating the governance of compassion in the humanitarian imaginary. International Theory, 6(2), 255-292.

Klüver, H., Mahoney, C., \& Opper, M. (2015). Framing in context: How interest groups employ framing to lobby the EU Commission. JEPP, 22(4), 481-498.

Lecheler, S., Bos, L., \& Vliegenthart, R. (2015). The mediating role of emotions: News framing effects on opinions about immigration. Journalism \& Mass Communication Quarterly, 92(4), 812-838.

Marcus, G. E., Mackuen, M., \& Neuman, W. R. (2011). Parsimony and complexity: Developing and testing theories of affective intelligence. Political Phycology, 32(2), 323-336.

McDermott, R. (2004) The feeling of rationality: The meaning of neuroscientific advances for political science. Perspectives on Politics, 2(4), 691-706.

Popa, M., \& Salanță, I. J. (2013). Emotions in the organizational environment. Annals of Faculty of Economics, 1(1), 1595-1605. 
Redlawsk, D. P. (2006). Feeling politics. Emotion in political information processing. Houndmills: Palgrave.

Sanchez Salgado., R. (2014). Europeanizing civil society: How the EU shapes civil society organizations. Houndmills: Palgrave.

Sanchez Salgado, R. (2017). Collective action \& emotions in multilevel systems. Paper Presented at Asociación española de Ciencia Política (AECPA) [Spanish Association of Political Science], Area II: Las dinamicas del proceso politico en sistemas multinível [Issue 2: Political process dynamics in multilevel systems], Santiago de Compostela, Spain.

Schmid, H. B. (2014). The feeling of being a group: Corporate emotions and collective consciousness. In C. Von Scheve \& M. Salmela (Ed.), Collective emotions (pp. 3-16). Oxford: Oxford University Press.

Schmitter, P., \& Streeck, W. (1981). The organization of business interests: A research design to study the associative action of business in the advanced industrial societies of western Europe. Berlin: WZB.

Thompson, S., \& Hoggett, P. (2012). Politics and the emotions. New York, NY: Continuum.

Trapp, L., \& Laursen, B. (2017). Inside out: Interests' groups 'outside' media work as a means to manage 'inside' lobbying efforts and relationships with politicians. Interest Groups and Advocacy, 6, 143-160.

Thrall, T. (2006). The myth of the outside strategy: Mass media news coverage of interest groups. Political Communication, 23, 407-420.

Van Erp, J. (2008). The impact of 'naming and shaming' on business reputations. An empirical study in the field of financial regulation. Paper presented at ECPR, Utrecht, The Netherlands.

Von Scheve, C., \& Salmela, M. (2014). Collective emotions. An Introduction. In C. Von Scheve \& M. Salmela (Eds.), Collective Emotions (pp. xiii-xxiv). Oxford: Oxford University Press.

\section{About the Author}

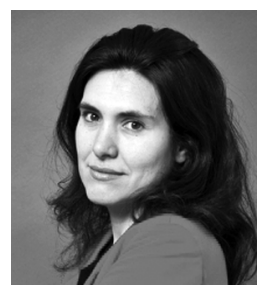

Rosa Sanchez Salgado is Assistant Professor of European Politics at the University of Amsterdam. Her research focuses on European politics and civil society organizations and social movements. She is currently analyzing the role of emotions in politics, including dynamics of public contestation and social change. She has published multiple articles on these topics in prestigious academic journals such as Journal of Common Market Studies and Journal of European Integration. Her last book: Europeanizing Civil Society: How the EU Shapes Civil Society Organizations (Palgrave) was published in 2014. 